\title{
SIGNIFICANT CHANGE IN MUSCULAR STRENGTH BASED ON THE HEAD AND NECK POSITION
}

\author{
Janis Vetra ${ }^{1}$, Vladimir Sklarevich ${ }^{2}$, Gregory AnoufrieV ${ }^{3}$, \\ ImANTS Kalninš ${ }^{4}$, Silvija UmbrašKo ${ }^{1}$, Janis Vetra JR ${ }^{5}$, \\ Vladislavs Kotovs ${ }^{6}$, LARISA BeILINA ${ }^{7}$ \\ ${ }^{1}$ Department of Morphology, Riga Stradiňš University, Riga, Latvia \\ ${ }^{2}$ Laboratory of Biomechanics, Riga Stradinš University, Riga, Latvia \\ ${ }^{3}$ Department of Health and Exercise Science, College of Health Sciences, \\ Appalachian State University, USA \\ ${ }^{4}$ Department of Physics, Riga Stradiňs University, Riga, Latvia \\ ${ }^{5}$ Faculty of Medicine, Riga Stradiňš University, Riga, Latvia \\ ${ }^{6}$ Clinic "Gimenes veselïba", Daugavpils, Latvia \\ ${ }^{7}$ Department of Mathematical Sciences, Chalmers University of Technology \\ and Gothenburg University, Sweden
}

\begin{abstract}
We present our study of the influence of the head 30 degrees flexion position on the changes in the muscle strength of the upper extremities. This position is typical for a person working in front of a computer.

The study involved 100 healthy volunteers and was performed at the Department of Morphology in Riga Stradiņš University, Riga, Latvia. For measurements we have used the MicroFET2 Hand Held Digital Muscle Tester to determine the strength of the muscles of the hand and the arm (M. deltoideus, M. biceps brachii, M. triceps brachii, M. abductor pollicis longus). The results of measurements were then used to analyze the difference in the strength of the muscles innervated by the spinal cord cervical region (C5-C8 nerves) for the same person sitting in the vertical position and sitting with the head flexed at $30^{\circ}$.

The results of our study support the hypothesis that the changes in the strength of the measured muscles are related to the mechanical distension of the spinal cord, which leads to changes in spinal cord's blood supply. The kyphosis position of the cervical spine during head flexion at $30^{\circ}$ extent shows
\end{abstract}


that in the spinal cord segments C5, C6 and C7 are form mechanical distension, but the changes in segment $\mathrm{C} 8$ were not detectable.

Using our statistical study, we can conclude that there is strong relationship in the strength change in most of the observed muscles between the vertical position and the flexion of head at 30 degrees.

Keywords: muscle strength of the upper extremities; spinal cord; cervical region flexion; work environment

\section{INTRODUCTION}

The goal of this research was to find out the possible reasons of changes in muscle strength in the targeted muscles of the arm and the hand (M. deltoideus, M. biceps brachii, M. triceps brachii and M. abductor pollicis longus) after the flexion of the head at $30^{\circ}$.

The study involved 100 healthy volunteers (68 women and $32 \mathrm{men}$ ), 19 to 30 years old. In our study we have used the MicroFET2 Hand Held Digital Muscle Tester in accordance with the manufacturers recommendations, in order to determine the strength of the muscles of the hand and the arm. The results were then used to analyze the difference in the strength of the muscles innervated by the spinal cord cervical region with the head flexed at $30^{\circ}$ and for the same person sitting in the vertical position of head. Our statistical results were obtained by using IBM SPSS software package Statistics20.

The rehabilitation professionals who work in clinical settings observed and described a well-known phenomenon: often, the patients' muscle strength in the arms changes asymmetrically when tilting the patient's head forward (flexio capitis) [1]-[6]. This means that changes in the muscle strength of the upper limb occur when changes in the cervical region take place (in the position of kyphosis, when no lordosis is present). This information can be found in the mechanical geometric explanation.
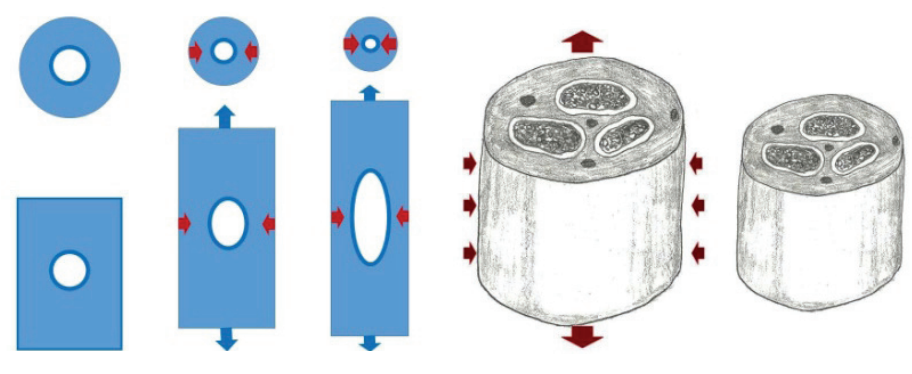

Figure 1. Deformation of structure in the elastic cylinder, such as the spinal cord or the nerve during the flexion of the spine. 
Often the flexion of the head is resulted in the change of the strength of the limb muscles. This fact cannot be explained by the geometry of the vertebral column. The available scientific literature sources mention this phenomenon, see for example, [7], but the information they provide is based on the patient observation only. No explanations are given with regards to its possible cause. Hereby, we are trying to clarify the nature of this phenomenon and establish certain parameters, in order to better understand it.

In this context, we conducted a feasible study involving healthy voluntary subjects, as well as using the data obtained from rehabilitation practitioners on the patients in clinical observation. Our experimental study has allowed us to identify the following:

- Manually verifiable changes in the upper limb muscle strength. The ability to change the spine curves from lordosis to the kyphosis are presented in all subjects, both healthy and with locomotion apparatus pathology, with a varying degree of expressiveness. Changes in the arm's muscle strength, by our experience, gives a universal response to a movement of the spine.

- The reduction of the muscle strength occurs immediately after the cervical spine lordosis changes in the position of kyphosis. After restoring normal lordosis, the muscle strength reduction disappears.

- The reduction of the upper limb muscle strength is always asymmetrical. This phenomenon is more expressed for the patients with chronic neck and shoulder pain.

- When the flexion of the head is within a physiological range, our test does not cause pain in the locomotion apparatus.

We are taking into consideration the changes in the upper limb muscle strength which are synchronized with the changes in the spinal functional curvature stage. We can assume that such a phenomenon could cause changes only in the conductivity of the central nervous system (spinal cord). The structures of the peripheral nervous system, including spinal nerves, does not change, but the area of their exit from the spine (intervertebral foramina) is widening during body flexion - see Figure 2 . 


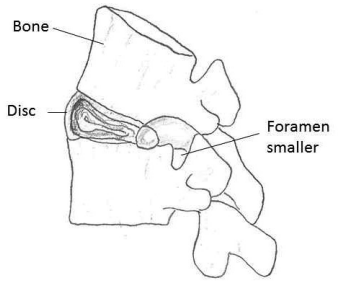

(a) Extension

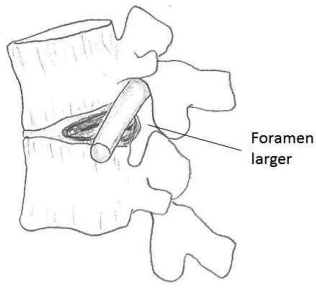

(b) Flexion

Figure 2.

As you see, enlarging of intervertebral foramina's sizes during the head flexion cannot be the reason of the nerve's irritation and the decline of the limb muscles strength. Changes in the elements of the musculoskeletal (locomotion) apparatus such as ligaments, tendons, bones, cartilage, or muscles, also cannot explain upper limbs muscles strength changings, because those occur very rapidly-during simple head flexion movement and they are quickly reversible. The kyphotic curvature of the cervical spine in its functional stage leads to a mechanical stretch and the functional change of the spinal cord, disturbing of blood circulation, see Figures 1, 3, 4. - that is the most possible reason of transitory segmentary innervated muscles strength changing.
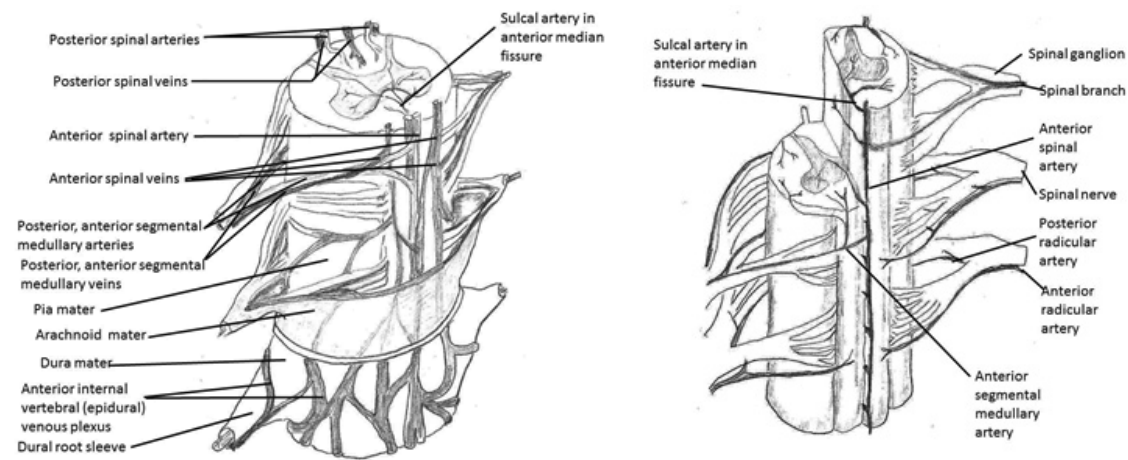

Figure 3. Spinal cord and intervertebral nerve's arteries. 


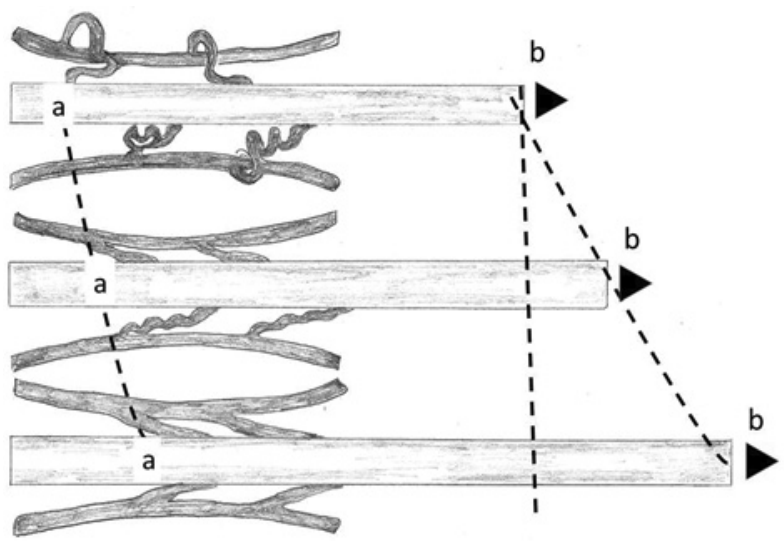

Figure 4. Small blood vessels "a" between the nerve fibers "b" of spinal cord.

The purpose of our research is to study various related changes in the muscle strength, as well as to find out what level of spinal cord changes could be attributed as a possible cause for this phenomenon and the findings in the clinical practice. Thus, the main goal of our research is to measure the relative changes in the muscle strength in specific muscles of the arm (M. deltoideus, M. biceps brachii, M. triceps brachii, M. abductor pollicis longus) when the cervical spine is in vertical position and while the head is flexed at $30^{\circ}$. This position is important in order to determine the possible reasons for the changes in muscle innervation and strength, because it is very typical for a person working in front of a computer.

\section{MATERIALS AND MEASUREMENT METHODS}

Our study has been approved by the Ethics Committee of Riga Stradiņš University (RSU), resolution number 55/29.01.2015, Chairperson Professor Olafs Bruvers. The date of approval is 29.01.2015.

In our study 100 volunteers in the age from 19 to 30 years old, with no health issues, were involved, see Table 1, for volunteer demographics. Volunteers have given their informed consent for the participation in the research study. All measurements were performed on the persons in the sitting position, using a standardized chair DXR ACER. The functional elements of the chair were adjusted in such a way so that the individuals' elbow joints should be at $90^{\circ}$ - arms should be supported on the armchair and the lumbar region of the spine column had individually adaptive support to maintain the lumbar region of the tested person in a fixed lordosis position. 
Table 1. Volunteer demographics

\begin{tabular}{lccc}
\hline Age & Female & Male & Total \\
\hline 19 & 5 & 5 & 10 \\
\hline 20 & 28 & 11 & 39 \\
\hline 21 & 25 & 11 & 36 \\
\hline 22 & 3 & 2 & 5 \\
\hline 22 & 3 & 2 & 5 \\
\hline 23 & & 1 & 1 \\
\hline 24 & 1 & & 1 \\
\hline 25 & 2 & & 2 \\
\hline 26 & 1 & 1 & 2 \\
\hline 27 & 1 & 1 & 2 \\
\hline 28 & 1 & & 1 \\
\hline 30 & 1 & & 1 \\
\hline Total & 68 & 32 & 100 \\
\hline
\end{tabular}

We used the MicroFET2 Hand Held Digital Muscle Tester according to the manufacturer's recommendations. In our tests we measured the strength of the muscles of the hand, the arm (M. deltoideus, M. biceps brachii, M. triceps brachii, and M. abductor pollicis longus), see Figure 5 for the experimental setup. Each muscle test was performed at least twice (with one repetition). The time which was spent for each test of the muscle measurement was the same. This time was determined automatically by the MicroFET2 Hand Held Digital Muscle Tester manual test system. We finished the test only when we got a message "valid" on the machine display. All measured results of the strength of the muscles were given in Newtons $N=\mathrm{kg} \cdot \mathrm{m}$. The trials were performed on the same subjects to determine the strength of the same muscles in two different body positions. Each produced the result of the measurement of the muscle strength and it was recorded when the cervical spine was in vertical position and during the flexion of the head at $30^{\circ}$.

The main tendency is described by the average value and distribution by the standard deviation. A T-test pairs of samples were used to determine if the developed muscle strength and the flexion of the spine in a vertical position are statistically significantly $(p<0.05)$ different. All measured results were processed by using the computer program IBM SPSS Statistics 20 .

To estimate standard deviation, we use the measurements for 100 persons of Table 1 . These measurements were performed at least twice for every person. 

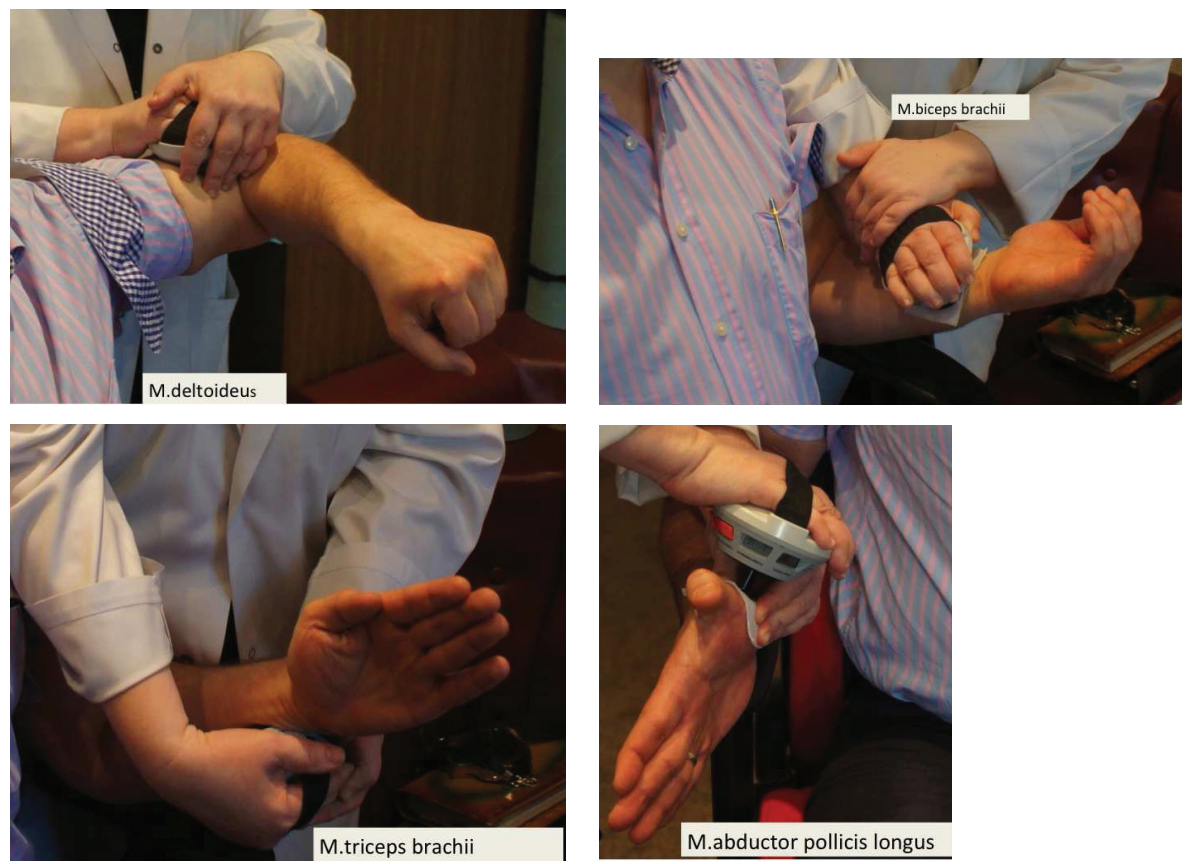

Figure 5. Experimental setup for measurements of the strength of the muscles of the hand and the arm.

\section{ANALYSIS OF RESULTS}

All results of measurements are presented in Tables 2, 3. The results in these tables show statistically significant changes in three of four muscles we tested (M. deltoideus, M. biceps brachii, M. triceps brachii) when the maximum strength values are obtained for the cervical spine in the vertical position and when the head is flexed at $30^{\circ}$. We have established that the potentially affected areas of the functional changes in the spinal cord are the C5, C6 and C7 segments, which are responsible for the corresponding muscle innervation (C5 for M. deltoideus, C6 for M. biceps brachii, C7 for M. triceps brachii).

We find statistically significant differences between the muscle strength of the spine in the vertical position and the flexio capitis (head flexion) position for 3 of 4 pairs of tested muscles. We supposed the possible reason that could lead to a rapid and reversible change in the innervation of the three muscles on the right and the left side is a mechanical stretch of the spinal cord and the changes in the blood supply to the spinal cord. Once again, we emphasize that it is a normal function of the locomotion apparatus in healthy subjects, not associated with pain or any subjective or functional impairment. The mechan- 
ical nervous stretch with an elongation within $5-12 \%$ range may cause the transient disturbances in innervation, see Figures 1, 3 and 4. Since the spinal cord is made of nervous tissue, it can be assumed that this mechanism could be one of the reasons for the relative change in the muscle strength phenomenon. During a longitudinal stretch of peripheral nerves, the increase in intraneural pressure occurs in proportion to the width of the nerves (Figure 1).

Table 2. Summary of measurements. The mean values of the extremities' muscle strength. Abbreviations: $v$ - the spine is vertical; $f$ - flexio capitis; $I$ - the left side; $r$ - the right side; digits - the size of the number in the database. For example: v1l - Abductor Pollicis Longus - the left side muscle, spine upright

\begin{tabular}{llccccc}
\hline & Muscles & \multicolumn{2}{c}{$\begin{array}{c}\text { The average } \\
\text { value(N) }\end{array}$} & $\begin{array}{c}\text { Standard } \\
\text { deviation } \rho \text {, (N) }\end{array}$ & $\begin{array}{c}\text { Statistical } \\
\text { Significance } \mathbf{p}\end{array}$ \\
\hline Pair 1 & $\begin{array}{l}\text { v1l Abductor Pollicis Longus } \\
\text { f1l Abductor Pollicis Longus }\end{array}$ & 51.1 & 53.3 & 26.1 & 26.5 & 0,092 \\
\hline Pair 2 & $\begin{array}{l}\text { v2l Biceps Brachii } \\
\text { f2l Biceps Brachii }\end{array}$ & 123.1 & 113.2 & 56.8 & 49.3 & 0.004 \\
\hline Pair 3 & $\begin{array}{l}\text { v3l Triceps Brachii } \\
\text { f3l Triceps Brachii }\end{array}$ & 121.4 & 108.6 & 57.0 & 52.0 & $<0.001$ \\
\hline Pair 4 & $\begin{array}{l}\text { v4l Middle Deltoid } \\
\text { f4l Middle Deltoid }\end{array}$ & 107.3 & 96.9 & 45.4 & 43.6 & $<0.001$ \\
\hline Pair 5 & $\begin{array}{l}\text { v5r Abductor Pollicis Longus } \\
\text { f5r Abductor Pollicis Longus }\end{array}$ & 50.3 & 51.0 & 29.5 & 27.1 & 0.678 \\
\hline Pair 6 & $\begin{array}{l}\text { v6r Biceps Brachii } \\
\text { f6r Biceps Brachii }\end{array}$ & 144.7 & 133.1 & 68.5 & 62.4 & 0.006 \\
\hline Pair 7 & $\begin{array}{l}\text { v7r Triceps Brachii } \\
\text { f7r Triceps Brachii }\end{array}$ & 132.3 & 120.2 & 57.6 & 50.3 & $<0.001$ \\
\hline Pair 8 & $\begin{array}{l}\text { v8l Middle Deltoid } \\
\text { f8l Middle Deltoid }\end{array}$ & 107.6 & 99.1 & 44.1 & 41.8 & $<0.001$ \\
\hline
\end{tabular}

The blood supply to the spinal cord system is complex, with high adaptability under various functional conditions, and it is composed out to three large longitudinal arterial trunks. Together, these trunks constitute a single circulatory circle. On the other hand, the spinal cord gray and white matter has blood supply which is carried out by the segmental artery and terminal branches. These arteries are perpendicular to the longitudinal axis of the spinal cord, see Figures 3, 4. Using our experimental study, we can conclude that the changes in blood supply will be directly affected by the spinal cord deformation caused by the mechanical stretch [7]. Because of this, it is most likely that the segmental vessels will be compressed, worsening the blood supply of 
the segment. At the same time, the neural functional capabilities are directly dependent on the adequate blood supply [8-10].

Overall, we are confident that, combining the main results of this study, the head flexion at $30^{\circ}$ can change the relative strength muscles of upper extremities. Since we have not found any statistically significant changes in the muscle strength in the M. abductor pollicis longus being innervated from C8 segment, we can conclude that the flexion of the head has created a mechanical stretch mostly of the segments $\mathrm{C} 5-\mathrm{C} 7$ and the neutral mechanical stretch is in the $\mathrm{C} 8$ segment.

Table 3. Changes in the limb muscle strength measured in Newtons $(\mathrm{N})$ in the spine (in the vertical position with flexed cervical and lumbar spine) compared to the left and right sides. Values in brackets show standard deviation $\rho$ in Newtons $(\mathrm{N})$

\begin{tabular}{lcccc}
\hline & \multicolumn{4}{c}{ Left side } \\
\cline { 2 - 5 } & $\begin{array}{c}\text { Abductor pollicis } \\
\text { longus }\end{array}$ & Biceps brachii & Triceps brachii & $\begin{array}{c}\text { Deltoid, } \\
\text { middle part }\end{array}$ \\
\hline Vertical & $51.1(26.1)$ & $123.1(56.8)$ & $121.4(57.0)$ & $107.3(45.4)$ \\
\hline Flexion & $53.3(26.5)$ & $113.2(49.3)$ & $108.6(52.0)$ & $96.9(43.6)$ \\
\hline Stat. significance $\mathrm{p}$ & 0.092 & 0.004 & $<0.001$ & $<0.001$ \\
Strength change\% & 4.4 & -8.1 & -10.5 & -9.6 \\
\hline
\end{tabular}

\begin{tabular}{lcccc}
\hline & \multicolumn{4}{c}{ Right side } \\
\cline { 2 - 5 } & $\begin{array}{c}\text { Abductor pollicis } \\
\text { longus }\end{array}$ & Biceps brachii & Triceps brachii & $\begin{array}{c}\text { Deltoid, } \\
\text { middle part }\end{array}$ \\
\hline Vertical & $50.3(29.5)$ & $144.7(68.5)$ & $132.3(57.6)$ & $107.6(44.1)$ \\
\hline Flexion & $51.0(27.1)$ & $133.1(62.4)$ & $120.2(50.3)$ & $99.1(41.8)$ \\
\hline Stat. significance $p$ & 0.678 & 0.006 & $<0.001$ & $<0.001$ \\
\hline Strength change\% & 1.3 & -8.0 & -9.1 & -7.9 \\
\hline
\end{tabular}

\section{DISCUSSION}

Changing the position of the head and the neck from neutral-cervical lordosis to flexed-cervical kyphosis results in the big mechanical overloading in the structure of the spine cervical region, see Figure 8 . That overloading can bring musculoskeletal disorders and shoulder-neck pain when that position becomes fixed during a long period of time [2,3].

The cervical spine position changes kyphosis to lordosis physiological extent, by flexio capitis 30 extent, leads to a significant change in the muscle 
strength between the right and the left side, that is causing the asymmetric changes in the arm muscle (M. deltoideus, M. biceps brachii, M. triceps brachii) strength.

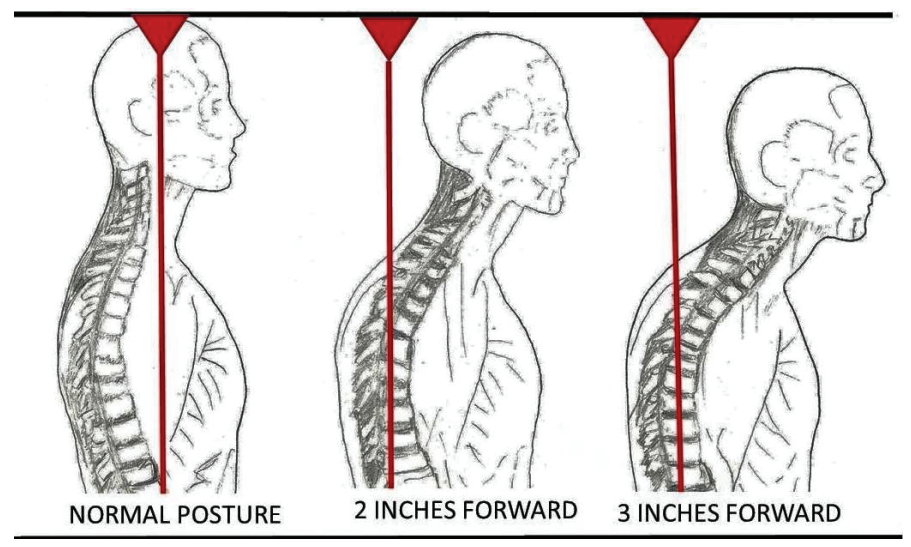

Figure 8. Different loading of the cervical region in the vertical position: $5.5 \mathrm{~kg}$ (left figure), head flexion 15 grades - $14.5 \mathrm{~kg}$ (middle figure), head flexion 30 grades - $19.5 \mathrm{~kg}$ (right figure).

The position of the regular computer user affects the strength in some of the upper limb muscles. The posture and the functional status of the spinal cord are important factors in various spinal pathology-related diseases. These factors must be taken into consideration because the flexion of the neck, and the position of the body may be overextended in some periods of time, on a daily basis, see Figures 8.

\section{CONCLUSION}

Using our statistical study, we can conclude that there is strong relationship in the change in some of the observed muscles (M. deltoideus, M. biceps brachii, $\mathrm{M}$. triceps brachii) between the vertical position and the flexion of the head at 30 degrees. The results of our study support the hypothesis that the changes in the strength of these muscles are related to the mechanical distension of the spinal cord, which leads to the changes in the blood supply to the spinal cord. The kyphosis position of the cervical spine, at flexio capitis $30^{\circ}$ extent, according to the indirect signs, that is, the changes in the muscle strength, show that in the spinal cord segments C5, C6 and C7 mechanical distension is formed, but changes in segment $\mathrm{C} 8$ were not detectable. 


\title{
REFERENCES
}

1. Hagberg M., Wigaeus Tornqvist E., Toomingas A. (2002). Self-reported reduced productivity due to musculoskeletal symptoms: associations with workplace and individual factors among white-collar computer users. J. Occup Rehabil, 12(3), 151-62.

2. Hales T.R., Sauter S.L., Peterson M.R., Fine L.J., Putz-Anderson V., Schleifer L.R., Ochs T.T., Bernard B.P. (1994). Musculoskeletal disorders among visual display terminal users in a telecommunications company. Ergonomics, 37, 1603-21.

3. Holte K.A., Westgaard R.H. (2002). Daytime trapezius muscle activity and shoulder neck pain of service workers with work stress and low biomechanical exposure. Amer. J Ind Med, 41, 393-405.

4. Theorell T., Harms-Ringdahl K., Ahlberg-Hultén G., Westin B. (1991). Psychosocial job factors and symptoms from the locomotor system - a multicausal analysis. Scand J Rehabil Med, 23, 165-73.

5. Wahlström J., Hagberg M., Toomingas A., Wigaeus Tornqvist E. (2004). Perceived muscular tension, job strain, physical exposure, and associations with neck pain among VDU users; a prospective cohort study. Occup Environ Med, $61,523-8$.

6. Vasseljen O., Holte K.A., Westgaard R.H. (2001). Shoulder and neck complaints in customer relations: individual risk factors and perceived exposures at work. Ergonomics, 44(4), 355-72.

7. Michael Shacklock Clinical Neurodynamics. A new system of musculoskeletal treatment. Elsevier, 2005.

8. FujitaY., Yamamoto H. Tani. (1998). An experimental study of spinal cord traction syndrome, Nippon Seikeigeka Gakkai Zasshi, 62, 359-368.

9. Lundborg G., Rydevik B. (1973). Effects of stretching the tibial nerve of the rabbit: a preliminary study of the intraneural circulation and barrier function of the perineurium. Journal of Bone and Joint Surgery, 55B, 390-401.

10. Ogata K., Naito M. (1986). Blood flow of peripheral nerve effects of dissection, stretching and compression. Journal of Hand Surgery, 11B,10-14.

11. Denny-Brown D., Doherty M. (1945). Effects of transient stretching of peripheral nerve. Archives of Neurology and Psychiatry, 54,116-129.

\author{
Address for correspondence: \\ Janis Vetra \\ Institute of Anatomy and Anthropology \\ Riga Stradiņš University \\ Riga, Latvia \\ E-mail: janis.vetra@rsu.lv
}

